\title{
ESPÉCIES NOVAS DE MYRCIA DC. E MARLIEREA CAMBES. (MYRTACEAE)
}

\author{
Graziela Maciel Barroso' \\ Ariane Luna Peixoto
}

Recebido em 02.08.90. Aceito em 10.08.90

\begin{abstract}
RESUMO - O trabalho trata de espécies novas de Myrcia DC. e Marlierea Cambes., dois gêneros de Myrtaceae da subtribo Myrciinae, da Reserva Florestal de Linhares, Espírito Santo, Brasil. Na área são conhecidas 18 espécies de Myrcia, 5 das quais são agora descritas. $O$ gênero Marlierea está representado por 12 espécies, uma das quais é descrita como nova. Os novos taxa são ilustrados, e feitos comentários sobre relacionamento entre espécies afins.
\end{abstract}

Palavras-chave: Myrtaceae, Myrcia, Marlierea.

\begin{abstract}
This paper deals with new species of Myrcia DC. and Marlierea Cambes., two genera of Myrtaceae subtribus Myrciinae, from the Reserva Florestal of Linhares, Espírito Santo, Brazil. From this area, 18 species of Myrcia are known, 5 of which are new to science and described here. Marlierea is not as rich in species as Myrcia but it is represented by 12 species, one here described as new. The new species are illustrated and some remarks are made about their relationships.
\end{abstract}

Key-words: Myrtaceae, Myrcia, Marlierea.

\section{Introdução}

A Reserva Florestal de Linhares, de propriedade da Companhia Vale do Rio Doce (CVRD), situada no município de Linhares, norte do estado do Espírito Santo, ocupa uma área de cerca de 22.000 ha. florestados. A vegetação está constituída por um misto de espécies características da mata de tabuleiros (hiléia bahiana), de espécies da mata atlântica, algumas espécies amazônicas e outras de distribuição mais ampla, extrabrasileira. Uma das famí-

1 - Jardim Botânico do Rio de Janeiro, Rua Pacheco Leão 915, CEP 22460, Rio de Janeiro, RJ, Brasil. Bolsista do CNPq.

2 - Universidade Federal Rural do Rio de Janeiro, Instituto de Biologia, Caixa Postal 74 582, CEP 23851, Seropédica, Itaguaí, RJ, Brasil. Bolsista do CNPq. 
lias de plantas com maior representatividade, quer em número de indivíduos, quer em espécies (Peixoto \& Gentry, 1990), é a das Myrtaceae, da qual foram levantadas 96 espécies. Das três subtribos que integram a tribo Myrteae, foi a das Myrciinae que apresentou maior número de representantes, seguindo-se a das Eugeniinae; as Pimentinae são menos numerosas em gêneros e espécies.

Algumas das exsicatas estudadas correspondentes às Myrciinae, depois de muitas tentativas infrutíferas para identificá-las com espécies já conhecidas, foram considerados taxa novos para a ciência. Se levarmos em conta que o estudo das Myrtaceae do sudeste do Brasil foi feito por Berg (1857-1859) e não revisado desde então, não é de estranhar o fato de, ainda, aparecerem espécies novas nessa região, principalmente no gênero Myrcia, cujo total de representantes não é bem delimitado e talvez exceda a 300 (Mc Vaugh, 1969). Desse gênero, são descritas agora 5 espécies novas e uma para o gênero Marlierea.

Os binômios escolhidos para as espécies constituem homenagem a servidores da Reserva Florestal de Linhares, como Domingos A. Folli, Gilson L. Farias e Isaias A. Silva (in memorian), coletores de material botânico, treinados e experientes, que muito têm ajudado aos sistematas que estudam as plantas da Reserva. Outra espécie é dedicada ao casal Haroldo e Marli de Lima, taxonomistas que, também, estão desenvolvendo trabalho sobre plantas da Reserva. A espécie de Marlierea recebeu o nome de D. Sucre, botânico que por muitas vezes visitou e coletou.no norte do Espírito Santo, tendo vasta coleção depositada no herbário do Jardim Botânico do Rio de Janeiro.

\section{Resultados e Discussão}

Myrcia follii Barroso \& Peixoto (sectio Aulomyrcia) sp. nov. Figura 1a-c

Arbor ca. $14 \mathrm{~m}$ alta, caule terete, exophloeo aspero, ca. $13 \mathrm{~cm}$ diâmetro, ramis teretibus, glabrescentibus. Folia petiolata, oblonga, $20-22 \mathrm{~cm}$ longa, $7-$ $9 \mathrm{~cm}$ lata, carthacea, basi et apice acuta, discoloria, supra glabra, subtus pilosa, pilis dibrachyatis rufescentibus, deciduis; punctis glandulosis pellucidis inconspicuis; nervo medio supra tenue, impresso-canaliculato, subtus prominente, rufo-hirsuto; venis lateralibus ca. 30, tenuissimis, in ambabus paginis manifestis, patulis; intersecundariis tenuioribus quam lateralibus, parce ramosis et reticulum laxum parce conspicuum formantibus; nervo marginale intra marginum $3 \mathrm{~mm}$ arcuato. Petiolum ca. $1 \mathrm{~cm}$ longum, canaliculatum. Paniculae 2-nis brevi pyramidales $8-9 \mathrm{~cm}$ longae, terminales, rufo-pilosae, ramis compressis $2-3 \mathrm{~cm}$ longis, botryoidibus. Alabastrum rufo-pilosum, glandulosum, ca. $0,4 \mathrm{~cm}$ longum, hypanthio dense rufo-tomentoso, calycis lobis 5 , crebe glandulosis, membranaceis, inaequalibus, 2 parvis, 2 minimis et 1 majore, rotundato tegen- 
te alia; pétala glabra; ovário 3-loculare; stylus glabrus. Bacca glandulosa, rufo-pilosa, ca. $1,3 \mathrm{~cm}$ diâmetro, flava, calyce coronata.

Holotypus - Espírito Santo, Linhares, Reserva Florestal da CVRD, estrada da Farinha Seca, 23.XI.1988, fl. D.A. Folli 821, CVRD. Isotypus RB. Paratypus - Ibidem., 8.III. 1989, fr. G.L. Farias 255, CVRD. Isoparatypus RB.

Árvore com ca. de $14 \mathrm{~m}$ de altura, fuste cilíndrico de ritidoma áspero com ca. de $8 \mathrm{~m}$ de comprimento, ca. de $13 \mathrm{~cm}$ de diâmetro a altura do peito, diâmetro da copa ca. de $4 \mathrm{~m}$; ramos cilíndricos, glabrescentes. Folhas pecioladas, oblongas, de base e ápice agudos, com $20-22 \mathrm{~cm}$ de comprimento e $7-9 \mathrm{~cm}$ de largura, cartáceas, discolores, glabras na face ventral, pilosas na face dorsal, com pêlos dibraquiados, rufos, caducos; nervura central fina, impresso-canaliculada na face ventral, saliente e rufo-hirsuta na face dorsal; nervuras secundárias ca. de 30 pares, muito tênues, manifestas nas duas faces, nervuras intersecundárias um pouco mais finas que as laterais, ramificadas, formando retículo de malhas frouxas; nervura marginal a ca. de $0,3 \mathrm{~cm}$ distante da margem; pecíolo canaliculado, com ca. de $1 \mathrm{~cm}$ de comprimento. Inflorescências em panículas piramidais, até 3 no ápice dos ramos, com $8-9 \mathrm{~cm}$ de comprimento, rufo-pilosas, com ramos comprimidos de $2-3 \mathrm{~cm}$ de comprimento, botrióides. Botão floral oboval, rufo-piloso, glanduloso, com ca. de $0,4 \mathrm{~cm}$ de comprimento, hipanto densamente rufo-tomentoso, lobos caliciniais 5 , membranáceos, densamente glandulosos, desiguais entre si, dois menores, dois médios e um maior recobrindo os demais; pétalas glabras; ovário 3-locular,estilete glabro. Baga globosa, glandulosa, de início rufo-pilosa com ca. de $1,3 \mathrm{~cm}$ de diâmetro, quando madura de cor amarela, coroada pelo cálice persistente.

Myrcia follii Barroso \& Peixoto difere de Aulomyrcia lucida Berg var. grandifolia, que ocorre no Rio de Janeiro, pelas dimensões maiores das folhas, pelo indumento de pêlos dibraquiados, (não seríceos), lobos do cálice não ciliados e estilete glabro (não seríceo).

De Myrcia rufipila Mc Vaugh, que ocorre no Pará, com a qual segundo a chave de identificação publicada por Mc Vaugh (1969) participa de muitos caracteres comuns, difere pela panícula mais curta, de $8-9 \mathrm{~cm}$ de comprimento, lobos caliciniais glabros, ovário trilocular e frutos maduros amarelos. Myrcia rufipila Mc Vaugh apresenta panícula com cerca de $15 \mathrm{~cm}$ de comprimento, com pêlos castanhos a alvos e frutos maduros atropurpúreos. Como caracteres comuns às duas espécies podem ser citados o porte arbóreo, e as folhas cartáceas com a nervura média impresso-canaliculada na face superior, nervuras laterais e aréolas do reticulado muito tênues, porém visíveis em ambas as faces da lâmina.

Myrcia folli Barroso \& Peixoto ocorre em floresta alta, como integrante do estrato arbóreo inferior e é conhecida na região pelo nome "Araçá-coêlho"'. 


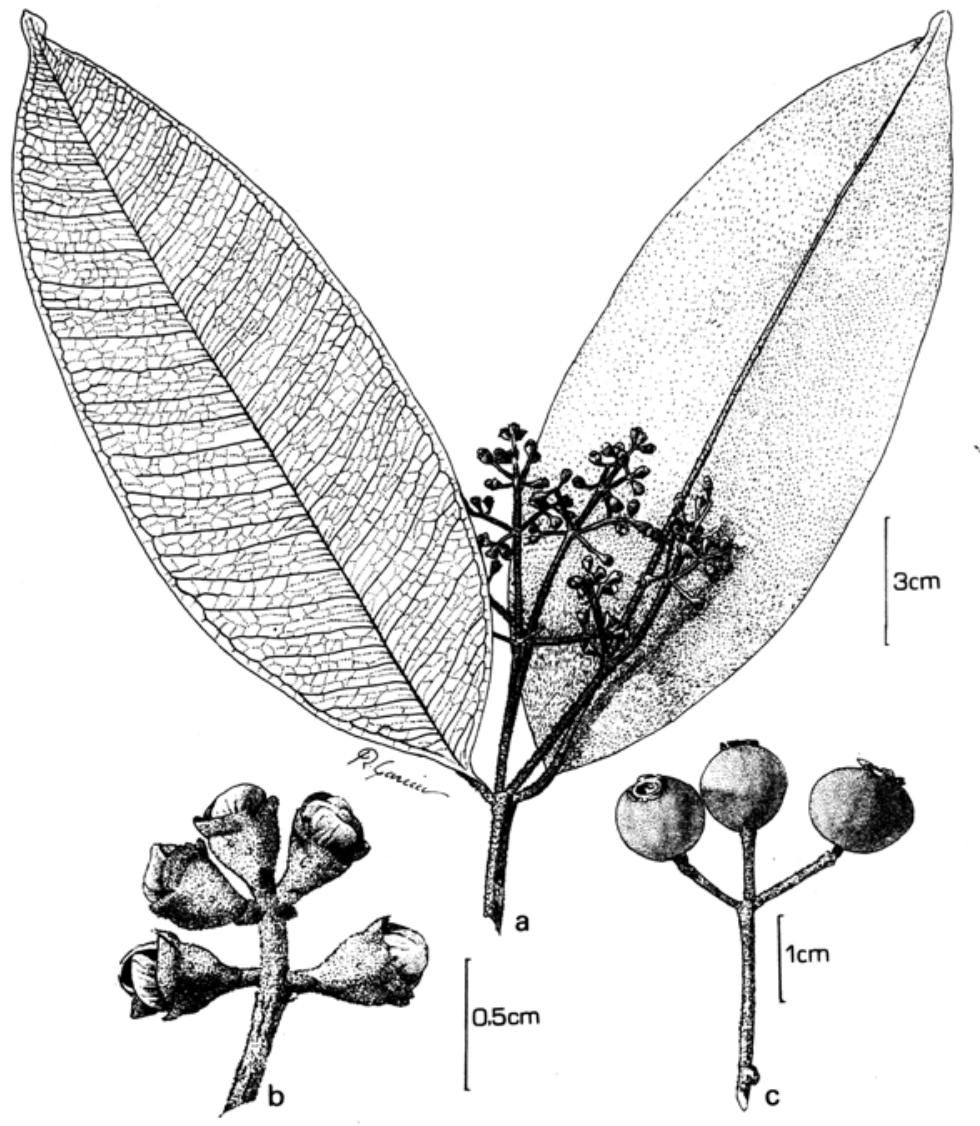

Fig. 1 - Myrcia follii: a. hábito; b. detalhe da inflorescência (D.A. Folli 821); c. fruto (G.L Farias 255). 
Myrcia gilsoniana Barroso \& Peixoto (sectio Aulomyrcia) sp. nov.

Figura 2a-c

Arbor ca. $12 \mathrm{~m}$ alta. Folia oblonga, apice et base acuta, ca. $12 \mathrm{~cm}$ longa, $3 \mathrm{~cm}$ lata, coriacea, supra glabra, lucida, subtus pilis dibrachyatis albis, brevis et deciduis, creberrima punctatis, glandulis minutissimis, fuscis, impellucidis, praecipue in foliis novellis, nervo medio supra lato et plano, canaliculato ad centrum, subtus incrassato, venis lateralibus utrinque 13-16, tenuibus, óblique erectis, intersecundariis vix conspicuis, parce ramosis, non reticulatis, nervo marginale ca. $0,3 \mathrm{~cm}$ a margine distante. Petiolum canaliculatum $1 \mathrm{~cm}$ longum. Panicula terminalis, multiflora, $10-12 \mathrm{~cm}$ longa, pilosa, pilis brevibus. Alabastrum clavato-turbinatum, glabrum, creberrime punctatum glandulosum ca. $4 \mathrm{~cm}$ longum base macula pili albi hirti, proxime insertionis ramorum disposita, hypanthio supra ovarium bilocularem valde producto in calycem 5-lobatum abiente, lobis inaequalibus late rotundatis, tandem patentibus.

Holotypus - Espírito Santo, Linhares, Reserva Florestal da CVRD, rio Barra Seca, próximo à casa do guarda, 8.XI.1972, fl. J.Spada 57, RB.

Árvore com ca. de $12 \mathrm{~m}$ de altura, fuste com ca. de $6 \mathrm{~m}$ de comprimento. Folhas oblongas, com ápice e base agudos, com ca. de $12 \mathrm{~cm}$ de comprimento e $3-4 \mathrm{~cm}$ de largura, coriáceas, glabras e lúcidas na página ventral, pilosas na face dorsal, com pêlos dibraquiados alvos, curtos e decíduos, densamente pontuadas de glândulas pequeníssimas, fuscas, não translúcidas, dispostas principalmente nas folhas jovens; nervura média plana e larga na face ventral, canaliculada no centro, espessada na face dorsal; nervuras laterais 13-16 pares muito tênues e pouco aparentes, obliquamente ascendentes, e nervuras intersecundárias pouco conspícuas, pouco ramificadas sem formar reticulado aparente, nervura marginal a ca. de $0,3 \mathrm{~cm}$ de distância do bordo do limbo. Pecíolo canaliculado, com ca. de $1 \mathrm{~cm}$ de comprimento. Panícula terminal multiflora, com $10-12 \mathrm{~cm}$ de comprimento, com raque aplanada, pilosa, sendo os pêlos curtos. Botão floral clavado-turbinado, glabro, minutamente glanduloso, com ca. de $\mathbf{0 , 4 \mathrm { cm }}$ de comprimento, provido na base, próximo à inserção dos ramos, de uma mancha de pêlos alvos e hirtos, hipanto muito prolongado acima do ovário bilocular, aberto em cálice 5-lobado, com lobos ligeiramente desiguais entre si, 4 triangulares e um arredondado, patentes na antese.

Myrcia gillsoniana é muito afim a Myrcia stictophylla (Berg) N. Silveira, distinguindo-se:

1. Pela forma das folhas um pouco diferente e de dimensões maiores. Além disso, em $M$. stictophylla (Berg) N. Silveira, tal como foi observado no exemplar-tipo e como sugere o nome específico, as folhas têm glândulas discoides bem desenvolvidas, esparsas, que podem ser observadas à vista desarmada. 
2. Pela panícula piramidal, com ramos patentes. Em $M$. stictophylla (Berg) N. Silveira a panícula é corimbosa, e foi por essa característica subordinada por Berg (1857) à seção Cymosae.

3. Pelas dimensões maiores dos botões florais, embora pela forma clavado-turbinada muito particular, assemelha-se aos de $M$. stictophylla (Berg) N Silveira.

A descrição de Myrcia (Aulomyrcia) stictophylla foi baseada em exemplar coletado por Sellow no Rio de Janeiro. Além do exame desse exemplartipo, depositado no Kew Herbarium, não se conseguiu identificar outro espécime nos diversos herbários consultados, cujas características concordassem com as descritas por Berg (1857). Este fato dificultou a comparação da espécie agora descrita com a única espécie a ela mais afim. A constatação da inexistência de exemplares de Myrcia stictophylla (Berg) N. Silveira em coleções de herbários bem como a não localização da espécie no campo faz supor que se trate de um taxon muito raro ou mesmo, já extinto.

Myrcia isaiana Barroso \& Peixoto (sectio Myrcia) sp. nov. Figura 3a-d

Arbor ca. 14m alta, caule terete, exophloeo aspero. Folia petiolata, elliptica vel elliptico-oblonga, novella pilis rufescentibus, tenuibus et brevis praecipue ad nervos dispositis; adulta glabrescentia, pilis persistentibus solum ad nervum medium et sparse ad venas; laminis $7,5-10 \mathrm{~cm}$ longis, $3,5-4 \mathrm{~cm}$ latis, coriaceis, basi obtusis, leviter emarginatis, apice apiculatis, apiculo triangulare ca. $0,15 \mathrm{~cm}$ longo, obsolete pellucido-punctatis, supra glabris, bullatis, nervo medio subtus elevato, venis lateralibus utroque latere 9-12, erecto-patulis, supra impressis, subtus prominulis, intersecundariis tenuibus, parce ramosis, non reticulatis, nervo marginale inter venas laterales arcuato, a margine $0,2-0,3 \mathrm{~cm}$ remoto. Petiolum rufo-pilosum, ca. $0,5 \mathrm{~cm}$ longum. Panicula $9-18 \mathrm{~cm}$ longa, ramis 2-4 teretibus, leviter patentibus, $4-8 \mathrm{~cm}$ longis, rufo-tomentosis. Alabastra $0,5 \mathrm{~cm}$ longa, rufo-tomentosa, hypanthio dense tomentoso, campanulato; calycis lobis 5 , ca. $0,2 \mathrm{~cm}$ longis, late rotundatis; petalis rotundatis $\mathrm{ca} .0,3 \mathrm{~cm}$ longis; ovario biloculare, loculis biovulatis. Bacca globosa, ca. 1,2cm diâmetro, calyce coronata.

Holotypus - Espírito Santo, Linhares, Reserva Florestal da CVRD, estrada Orelha-de-Onça, antiga 143, 15.IX.1978, fl, I.A. Silva 21, CVRD. Isotypi RB, RBR. Ibid., 14.XII.1988, fr, G.L. Farias 349, paratypi CVRD, RB. 


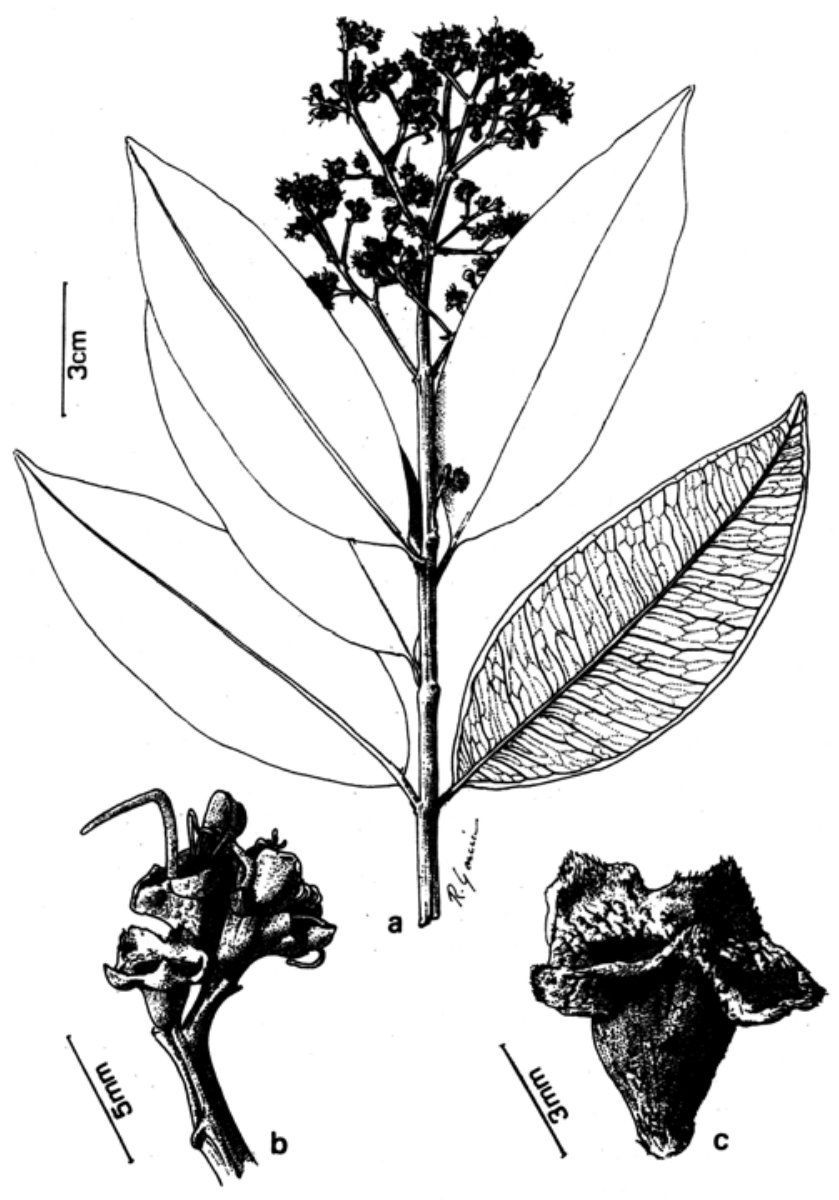

Fig. 2 - Myrcia gilsoniana: a. hábito; b. detalhe da inflorescência; c. detalhe da flor (J. Spada 57). 
Árvore com ca. de $14 \mathrm{~m}$ de altura, com fuste cilíndrico, de ca. de $9 \mathrm{~m}$ de comprimento, ritidoma áspero, diâmetro à altura do peito de até $31 \mathrm{~cm}$ e diâmetro da copa com ca. de $4 \mathrm{~m}$. Folhas elípticas e elíptico-oblongas, com base obtusa levemente emarginada, ápice apiculado, apículo triangular com ca. de $0,15 \mathrm{~cm}$ de comprimento, com 7,5-10 cm de comprimento e $3,5-4 \mathrm{~cm}$ de largura, coriáceas, folhas jovens com pêlos rufescentes, finos e curtos, dispostos principalmente sobre as nervuras, nas adultas, a pilosidade só persiste sobre a nervura média e, em menor proporção, sobre as nervuras laterais, obscuramente pelúcido-pontuadas, buladas; nervura média imersa na face ventral e saliente na face dorsal, nervuras laterais 9 a 12 pares, imersas na ventral, promínulas na dorsal, nervuras intersecundárias tênues, pouco ramificadas, sem formar reticulado aparente, nervura marginal mais ou menos arqueada entre as nervuras laterais e distante $0,2-0,3 \mathrm{~cm}$ do bordo do limbo. Pecíolo rufo-piloso, com ca. de $0,5 \mathrm{~cm}$ de comprimento, espessado. Panícula com $9-18 \mathrm{~cm}$ de comprimento, com 2-4 ramos cilíndricos, mais ou menos patentes, com $4-8 \mathrm{~cm}$ de comprimento, rufo-tomentosos, terminando por raminhos com 3 flores apicais congestas. Botões florais com ca. de $0,5 \mathrm{~cm}$ de comprimento, rufo-tomentosos, com hipanto densamente tomentoso, campanulado; lobos do cálice 5, orbiculares com ca. de $0,2 \mathrm{~cm}$; pétalos arredondados com ca. de $0,3 \mathrm{~cm}$; ovário bilocular com lóculos biovulados. Baga globosa com ca. de $1,2 \mathrm{~cm}$ de diâmetro, de início rufo-pilosa, quando madura de cor rósea, coroada pelo cálice persistente.

Em estádio vegetativo, pelo tipo de nervação das folhas, a espécie pode ser confundida com uma Gomidesia, mas as anteras muito pequenas, não têm as características daquelas tão peculiares das espécies desse gênero.

A princípio, inclinou-se a identificar o espécime como Myrcia maximiliana Berg, uma espécie do grupo "Bullatae” de Berg (1858) cujo exemplartipo foi coletado pelo príncipe Wied-Neuwied, em Ilhéus, BA. O hábito (frutex 3-pedalis), as nervuras laterais patentes, cerca de 25 pares, o ovário trilocular, 6-ovulado referidos na diagnose, induziram a buscar outras informações.

Mc Vaugh (1969) dá ampla informação sobre Myrcia deflexa (Poiret) DC, uma das Myrtaceae da América Tropical de mais ampla distribuição (Amazônia Peruana, as Guianas e Antilhas), dando como sinônimo dela, $M$. crassinervea DC. e $M$. sulcata Berg, das quais se analisaram fototipos. Com o exame dessas fotos (respectivamente FM 1919 e FM 36569) verificou-se que as folhas desses taxons são muito semelhantes às descritas para $M$. maximiliana Berg e $M$. schaueriana Berg, outra espécie do grupo "Bullatae", coletada por Sellow no Rio de Janeiro. Divergem porém do material estudado, não só pelo número maior de pares de nervuras laterais, como pela disposição patente delas.

O tipo de inflorescência, representada na foto de $M$. sulcata Berg, coincide com o de Myrcia isaiana Barroso \& Peixoto, mas Mc Vaugh descreve para ela um tipo de indumento constituído de uma mistura de pêlos eretos e agu- 
dos e pêlos finos, escamosos, com aparência glandular, que não foi observado no material estudad e assim permite concluir que o espécime da Reserva Florestal da CVRD, embora deva ter afinidades com $M$. deflexa (Poiret) DC., e talvez com $M$. schaueriana Berg e $M$. maximiliana Berg, é um taxon independente.

A nova espécie ocorre em floresta alta e é conhecida na região pelo nome "Luizinho".

Myrcia limae Barroso \& Peixoto (sectio Aulomyrcia) sp. nov. Figura 4a-c

Frutex foliis carthaceis, glabris, oblongo-spathulatis, $22-30 \mathrm{~cm}$ longis, supra medium, $7-8 \mathrm{~cm}$ latis, ad medium $6-6,5 \mathrm{~cm}$ latis versus apicem $4-3 \mathrm{~cm}$ latis, ad apicem $1,5 \mathrm{~cm}$ latis, versus basin $4-3 \mathrm{~cm}$ latis, ad basin $1,5 \mathrm{~cm}$ latis, apice leviter obtusis, base leviter emarginatis, brevi peltatis, petiolatis; nervum medium supra late applanatum, subtus prominulum, apicem versus attenuatum; venae laterales utroque latere 22-26, tenuissimae, in ambabus paginis manifestae, adscendentes, duplicato-limbinerves; intersecundariae tenuiories quam lateralibus, dense reticulatae; glandulae solum conspicuae supra nervum medium. Petiolum glabrum, planum convexum, ca. $1 \mathrm{~cm}$ longum. Bracteae 2, oblongae, acutae, foliaceae, oppositae, ad basin panicula dispositae. Panicula terminalis $25-30 \mathrm{~cm}$ longa, 4 internodiis $3-3,5 \mathrm{~cm}$ distantibus inter se, ramis erectis $12-13 \mathrm{~cm}$ longis, fastigiatis,imprimis simplicibus, interdum paris ramulis ordinis secundis patentibus, $3-4 \mathrm{~cm}$ longis ad basin bibracteolatis, bracteolis triangularibus $0,3-0,5 \mathrm{~cm}$ longis. Flores sessiles 5-6 supra pedunculum brevem alternatum agglomerati. Alabastrum obovatum $0,3 \mathrm{~cm}$ longum, pilosum, pilis hispidis brevis; calycis lobis 5 inaequalibus, 3 majoribus quam duobus; disco cupuliforme, grabro.

Holotypus - Espírito Santo, Linhares, Reserva Biológica de Sooretama, mata de tabuleiro, VIII. 1969, fl. D. Sucre 9660, RB. Ibidem, Santa Tereza, Rio Saltinho, 31.V.1984, fl. J.M. Vimercat 167, paratypi MBML, RB. 


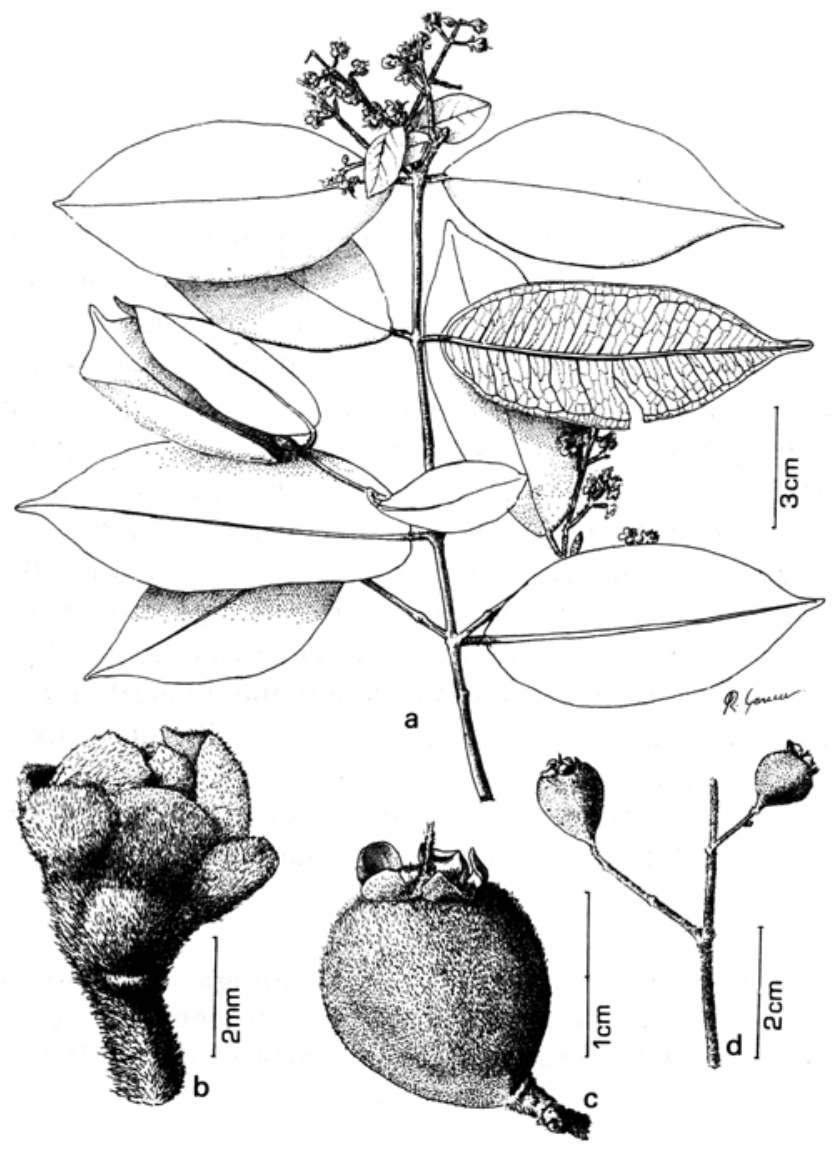

Fig. 3 - Myrcia isaiana: a. hábito; b. flor (G.L. Farias 349); c. ramo frutífero; d. fruto (I.A. Silva 21). 
Arbusto com folhas oblongo-espatuladas, levemente obtusas no ápice e curtamente emarginadas e peltadas na base, com $22-30 \mathrm{~cm}$ de comprimento, acima da porção mediana com $7-8 \mathrm{~cm}$ de largura, na porção mediana com $6-6,5 \mathrm{~cm}$ de largura, e na base com $1,5-2 \mathrm{~cm}$ de largura, glabras, nítidas, cartáceas; nervura média aplanado-alargada na face ventral, promínula no dorso, atenuada em direção ao ápice, nervuras laterais 22 a 26 pares, muito finas, manifestas nas duas faces do limbo, ascendentes, nervuras marginais 2 , a mais interna mais conspícua, nervuras intersecundárias mais finas que as laterais, reticuladas; glândulas só manifestas sobre a nervura média. Pecíolo glabro, plano-convexo, com ca. de $1 \mathrm{~cm}$ de comprimento. Panícula terminal, com duas brácteas foliáceas na base, com $25-30 \mathrm{~cm}$ de comprimento, ramos eretos, com $12-13 \mathrm{~cm}$ de comprimento, fastigiados principalmente simples mas, às vezes, com poucos pares de ramos de segunda ordem patentes, com $3-4 \mathrm{~cm}$ de comprimento, bibracteolados na base, com bractéolas triangulares com $0,3-0,5 \mathrm{~cm}$ de comprimento. Flores sésseis, de 5-6 aglomeradas sobre pendúnculo comum curto, alternado. Botão floral com ca. de $0,3 \mathrm{~cm}$ de comprimento, piloso, com pêlos hispidos, curtos; lobos do cálice 5, desiguais entre si, 3 maiores e 2 menores; disco cupulifome, glabro.

Myrcia limae, pelos conjunto de caracteres distintos, não mostra afinidades com nenhuma das espécies conhecidas.

A espécie ora descrita foi coletada na Reserva Biológica de Sooretama, no município de Linhares, em mata de tabuleiro e na Reserva Biológica de Santa Lúcia, no município de Santa Teresa, na mata atlântica. Essas duas formações florestais são distintas em diversos aspectos, inclusive pela composição florística. Algumas espécies, entretanto, compartilham das duas formações.

Myrcia riodocensis Barroso \& Peixoto (sectio Aulomyrcia) sp. nov. Figura 5a-b

Arbor ca. $10 \mathrm{~m}$ alta, exophloeo, laevissimi rubicundo lamellatim soluto; foliis oblongo-lanceolatis, coriaceis, glabris, $12-14 \mathrm{~cm}$ longis, $4-5 \mathrm{~cm}$ latis, apicem versus attenuato-acuminatis, basi obtusis, nervo medio supra tenue canaliculato, subtus prominente, venis lateralibus utroque latere 13-15, tenuissimis, patentibus, in ambabus paginis manifestis, intersecundariis tenuioribus quam lateralibus, laxe reticulatis, nervo marginale tenue ca. $0,2 \mathrm{~cm}$ a margine distante. Petiolum 0,1-0,2cm longum. Paniculae 2-oppositae, terminales, pyramidales, laxiflorae, ramis racemosis floribus umnibus brevi peduncullatis. Alabastrum turbinatum, glabrum, glandulorum $0,3-0,4 \mathrm{~cm}$ longum, calycis lobis 4 , inaequalibus, 2 longe apiculatis et 2 mutices apice rotundatis. 


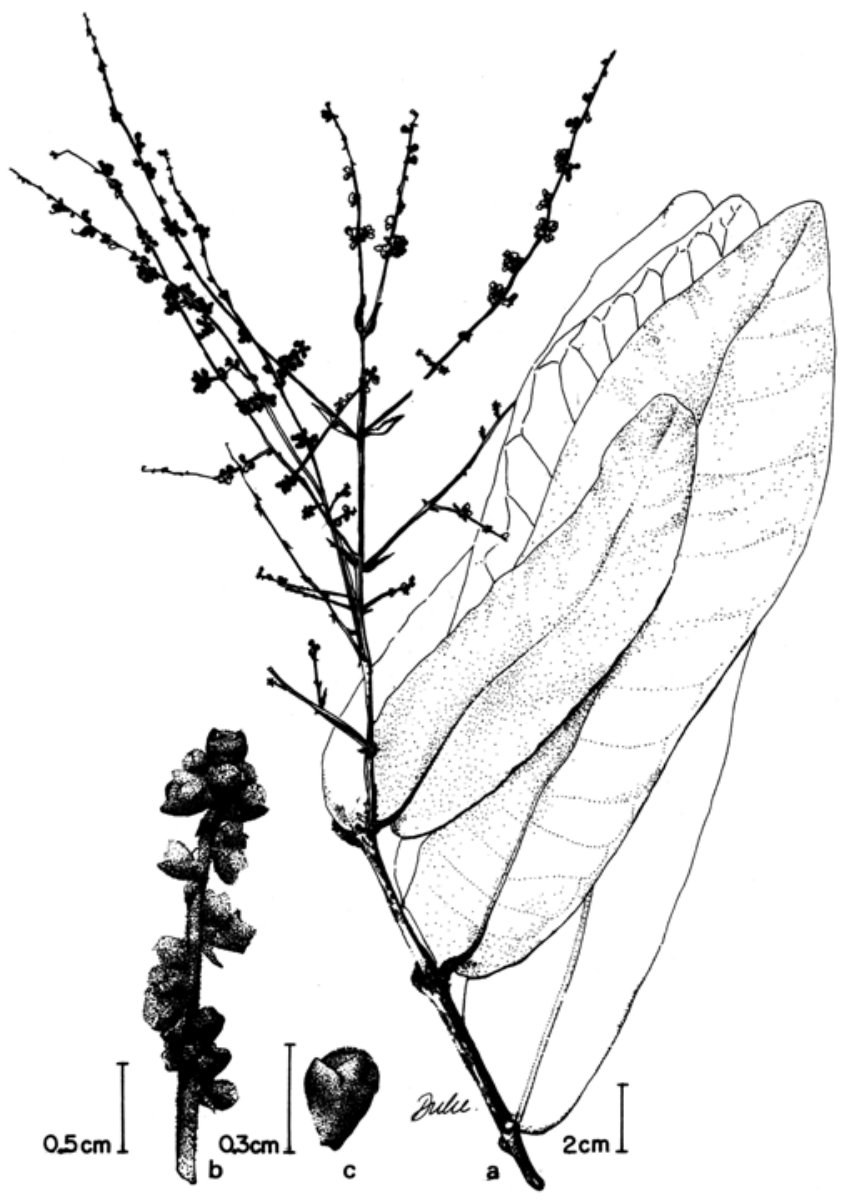

Fig. 4 - Myrcia limae: a. hábito; b. detalhe da inflorescência; c. botão floral (D. Sucre 9660). 
Holotypus - Espírito Santo, Linhares, Reserva Florestal da CVRD, Floresta alta, 30.I.1972, fl. D. Sucre 8269, RB. Isotypus CVRD. Ibidem, 20.II.1987, fl. A.L. Peixoto \& O.L. Peixoto 2331, Paratypus RBR.

Árvore com ca. de $10 \mathrm{~m}$ de altura, ritidoma avermelhado, esfoliante. Folhas oblongo-lanceoladas, atenuadas em direção ao ápice e obtusas na base, com $12-14 \mathrm{~cm}$ de comprimento e $4,5 \mathrm{~cm}$ de largura, coriáceas, glabras; nervura média muito fina, canaliculada na face ventral e saliente na face dorsal. sobressaindo-se do limbo, principalmente pela cor enegrecida depois de seca. nervuras laterais 13-15 pares, muito finos, patentes pouco manifestos nas duas faces do limbo; nervuras intersecundárias mais finas que as laterais, ramificadas formando reticulado frouxo, nervura marginal a ca. de $0,2 \mathrm{~cm}$ distante do bordo. Pecíolo 0,1-0,2cm de comprimento. Panículas terminais, 2-opostas, piramidais, laxifloras, com ramos dibotrióides; botōes florais turbinados, curtamente pedicelados, glandulosos, com $0,3-0,4 \mathrm{~cm}$ de comprimento, com 4 lobos caliciniais desiguais entre si, dois apiculado-mucronados e dois múticos, com ápice arredondado.

No tipo de panícula, pela forma, dimensões e reticulado das folhas, e pela flor tetrâmera, a espécie lembra Marlierea grandiflora Berg, mas o botão floral, embora tetrâmero é tipicamente de uma espécie de Myrcia (secão $\mathbf{A u}$ lomyrcia). A característica dos lobos caliciniais, marcante nessa espécie, parece não ter similar entre as espécies brasileiras de Myrtaceae.

Myrcia riodocensis Barroso \& Peixoto ocorre em floresta alta e destaca-se, no campo, pela cortex vermelho-escura, papirácea e pela inflorescência nitidamente 2-oposta.

Marlierea sucrei Barroso \& Peixoto sp. nov.

Figura 6a-d

Arbor 6-12m alta, exophloeo laevissimi, rubicundo, lamellatim soluto, ca. $9 \mathrm{~cm}$ diâmetro. Rami teretes, cataphyllis vaginantibus, superimpositis, membranaceis, dorso ferrugineo-tomentosis, supra glabris et glandulosis, ca. $13 \mathrm{~cm}$ longis, delapsis; foliis oblongis, discoloribus, coriaceis, pilosis vel glabrescentis, pilis dibrachyatis deciduis, $15-25 \mathrm{~cm}$ longis, $7-11 \mathrm{~cm}$ latis, apize abrupto-acuminatis, acumine ca. $1,5-2 \mathrm{~cm}$ longo, basi rotundatis, supra nervo medio applanato, dense glanduloso et pilis sparsis, subtus prominenti apicem versus attenuato, nervis lateralibus utroque latere 20-35 tenuibus, supra depressis, subtus leviter prominulis, intersecundariis tenuioribus quam lateralibus, laxe reticulatis. Petiolum plano convexum, robustum ca. $1,2 \mathrm{~cm}$ longum. Inflorescentia spiciformis $12-14 \mathrm{~cm}$ longa, rachi terete, robusta, ferrugineo-tomentosa, floribus 2-3 agglomeratis, agglomerato sparso, involucrato, involucro 4-bracteato, bractis ovatis, membranaceis, pilosis, ca. $1,5 \mathrm{~cm}$ longis, $0,7 \mathrm{~cm}$ latis. Alabastrum globosum $0,5-0,6 \mathrm{~cm}$ longum, ferrugineo-tomentosum, clausum, ante anthesim integerrimum, demum in Iobos 5, aequales, diseptum; disco cupuliforme glabro. Fructus globosi, ferrugineo-tomentosi, ca. 1,5 alti, calyce persistente, lobis erectis, acutis. 


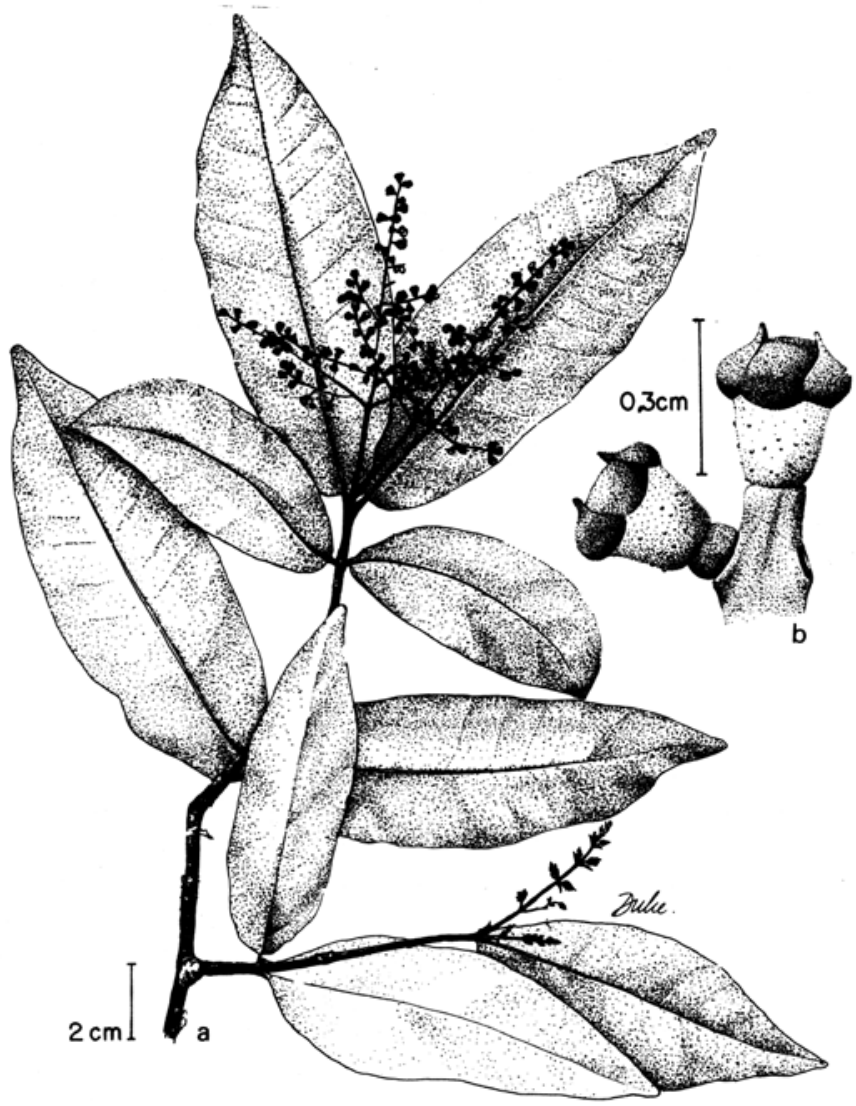

Fig. 5 - Myrcia riodocensis: a. hábito; b. botões florais (D. Sucre 8269). 
Holotypus - Espírito Santo, Linhares, Reserva Florestal da CVRD, 31.I.1972, fl. D. Sucre 8320, RB. Isotypi RB, RBR.

Paratypi - Ibidem, estrada da Gávea km 14.532, 30.XI.1982, fl. I.A. Silva 366, CVRD, RBR; Ibidem, estrada X-1, próximo a torre, 2.XI.1986, fl. fr. A.L. Peixoto \& O.L. Peixoto 1730, RBR. Bahia, Una, estrada que liga a BR 101 (São José) com a BA 265, 6.IV.1978, fr. S. Mori, J.L. Hage \& A. Lourtaig 9846, CEPEC, RB.

Árvore com 6-12m de altura, fuste cilíndrico de ritidoma liso, esfoliante em lâminas membranáceas, avermelhadas, diâmetro à altura do peito 8$10 \mathrm{~cm}$, diâmetro da copa ca. $3 \mathrm{~m}$; ramos cilíndricos, com catáfilos superpostos, invaginantes, que se desprendem em lâminas estreitas superpostos, membranáceos, ferrugineo-tomentosos no dorso, glabros e glandulosos na face ventral, de ca. de $13 \mathrm{~cm}$ de comprimento. Folhas oblongas, com ápice abruptamente acuminado, acumem com $1,5-2 \mathrm{~cm}$ de comprimento, base arredondada, com $15-25 \mathrm{~cm}$ de comprimento e $7-11 \mathrm{~cm}$ de largura, discolores, coriáceas, de glabrescentes a pilosas, sendo os pêlos dibraquiados, caducos; nervura média aplanada na face ventral, densamente glandulosa e com pêlos esparsos na face dorsal, atenuada em direção ao ápice, nervuras laterais 20-35 pares, muito finos, deprimidos na face ventral, levemente proeminentes no dorso, nervuras intersecundárias mais tênues que as laterais, laxamente reticuladas. Pecíolo plano-convexo, robusto com ca. de $1,2 \mathrm{~cm}$ de comprimento. Inflorescência espiciforme com $12-14 \mathrm{~cm}$ de comprimento, com raque cilíndrica, robusta, ferrugineo-tomentosa; flores 2-3 aglomeradas, aglomerado esparso, involucrado, com invólucro de 4 brácteas ovais, membranáceas, com ca. de $1,5 \mathrm{~cm}$ de comprimento de $0,7 \mathrm{~cm}$ de lagura, pilosas no dorso; botão floral globoso, com $0,5-0,6 \mathrm{~cm}$ de comprimento, ferrugíneo-tomentoso, integérrimo antes da antese, na antese fendido regularmente, até a porção superior do ovário, em 5 lobos coriáceos radiais, iguais entre si, glabros na face ventral, ferrugíneo-tomentosos no dorso, com ca. de $0,3 \mathrm{~cm}$ de comprimento; disco cupuliforme mais ou menos profundo e glabro. Frutos globosos, ferrugíneo-tomentosos a glabrescentes com ca. de $1,5 \mathrm{~cm}$ de comprimento, com lobos caliciniais persistentes, eretos.

Marlierea sucrei Barroso \& Peixoto é uma espécie ímpar, que não mostra afinidades com outra espécie de Myrtaceae conhecida. O botão floral aberto na antese em 5 lobos caliciniais regulares, não é característica muito comum entre as Marlierea. Desde 1972, quando pela primeira vez foi observada chamou a atenção a singularidade da espécie e, desde então não se pouparam esforços para identificá-la. Entretanto só agora decidiu-se por classificá-la, após a análise de vários exemplares de herbário e observações de espécimes vivos no campo.

A espécie é encontrada com freqüência no estrato arbóreo inferior da mata de tabuleiro. É conhecida pelo nome comum "Araçá-coelho" e facilmente reconhecida, no campo, mesmo quando estéril, pelas folhas de grandes dimensões e pelos catáfilos castanho-escuros, pêndulos, nos ápices dos ramos. 


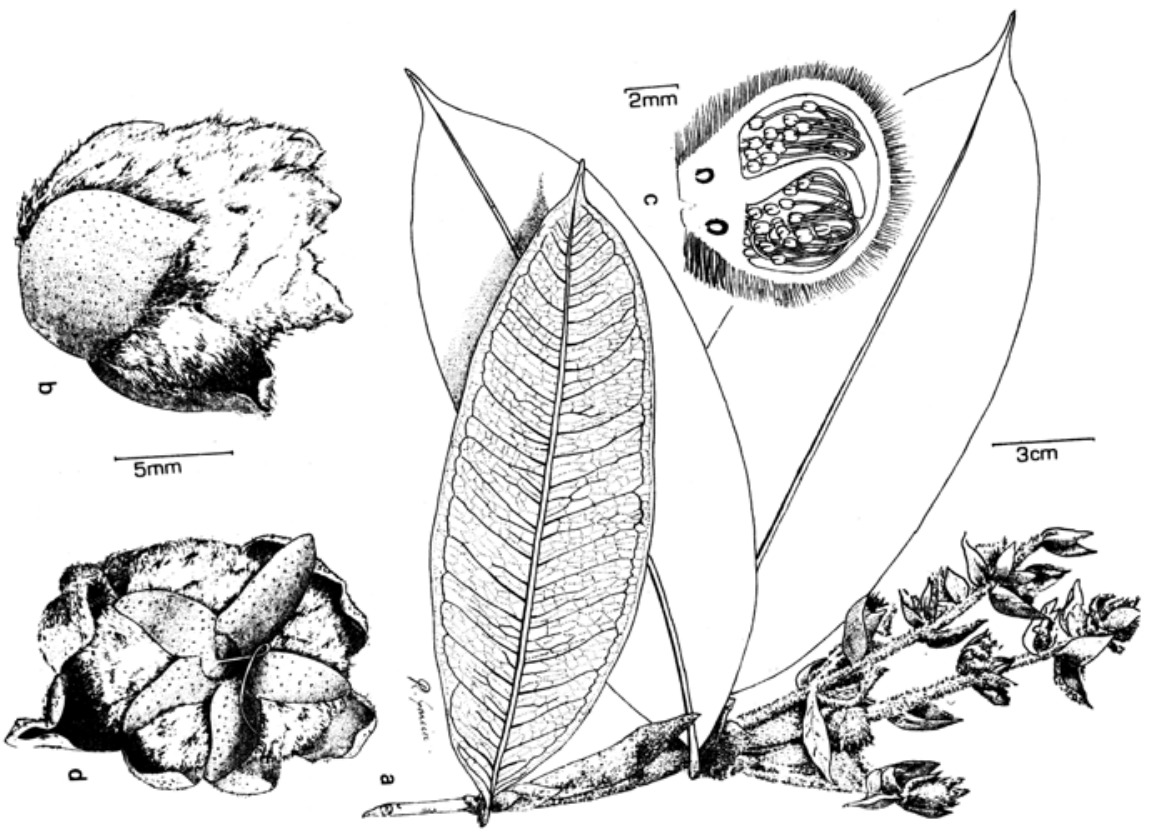

Fig. 6 - Marlierea sucrei: a. habito; b. botão floral; c. corte esquemático do botão floral; d. fruto (D. Sucre 8320). 


\section{Referências Bibliograficas}

BERG, O. 1857-1859. Myrtaceae. In: C.P.F., MARTIUS, Flora Brasiliensis 14(4): 28-38; 60-208.

MC VAUGH, R. 1969. The botany of the Guayana Highland - Part VIII. Mem. New York Bot. Gard. 18(2): 55-286.

PEIXOTO, A.L. \& A. GENTRY, 1990. Diversidade e Composição Florística de um Trecho de Mata Alta na Reserva Florestal de Linhares, Espírito Santo, Brasil. Rev. Brasil. Bot. 12: (no prelo). 